\title{
Identification of penicillinase producing Neisseria gonorrhoeae in Chile during clinical and microbiological study of gonococcal susceptibility to antimicrobial agents
}

\begin{abstract}
J GARCIA MORENO, *J R DILLON, †R ARROYAVE, ¥A MALDONADO, * F FICH, § A SALVO, ID VILLALOBOS, *P VINCENT, *AND M PAUZE $\dagger$

From the *Instituto de Salud Publica de Chile, Santiago, Chile, the $\dagger$ Antimicrobials and Molecular Biology Division, Laboratory Centre for Disease Control, Ottawa, Canada, the $¥$ Consultorio ETS Artessaros, the $\S$ Hospital Paula Jaraquemada, and the \Hospital Solero del Rio, Santiago, Chile
\end{abstract}

SUMMARY The first penicillinase producing isolates of Neisseria gonorrhoeae (PPNG) identified in Chile were discovered during a clinical and microbiological study to compare the efficacy of penicillin (4.8 MIU aqueous procaine penicillin G plus $1 \mathrm{~g}$ oral probenecid) and tetracycline ( $1.5 \mathrm{~g}$ followed by $500 \mathrm{mg}$ four times daily for four days) treatment regimens for acute uncomplicated gonorrhoea. Penicillin treatment was effective in $93.1 \%(282)$ of 303 patients, whereas tetracycline was effective in $98.3 \%$ (233) of 237 patients. Six of the penicillin treatment failures were attributable to PPNG strains. In all, 21 PPNG strains were identified during the study. They were genetically identical, having a wild type auxotype, a WII/III serotype (serovar Bajk), and carrying cryptic and transfer plasmids and an Asian type penicillinase producing plasmid.

In addition, 674 non-PPNG isolates were tested for their susceptibility to eight antimicrobials. Over $95 \%$ were sensitivie to $1 \mathrm{mg} / \mathrm{l}$ of penicillin, ampicillin, cefotaxime, cefuroxime, and erythromycin, over $90 \%$ were sensitive to $1 \mathrm{mg} / \mathrm{l}$ of tetracycline and $2 \mathrm{mg} / \mathrm{l}$ of thiamphenicol, and all were sensitive to spectinomycin. Of 226 non-PPNG isolates characterised for plasmid content and auxotype, $90 \%$ (205) were either wild type or proline requiring, 67\% (153) carried only the cryptic plasmid, and a further $31 \%$ (71) carried both cryptic and transfer plasmids. Unusually, three of four isolates lacking the cryptic plasmid carried only the transfer plasmid.

\section{Introduction}

During the 1980s the incidence of infections with Neisseria gonorrhoeae has either declined or remained stable in several countries of the developed world. ${ }^{1-3}$ In developing countries, however, there are indications, such as the increased isolation of penicillinase producing $N$ gonorrhoeae (PPNG) strains, that the incidence of gonococcal infection is increasing. It is difficult to ascertain the magnitude of the problem in these countries for various reasons. The absence of active surveillance and case finding activities, lack of treatment, self treatment, and a tendency to concentrate investigations on specific prostitute populations or on urban populations all

Address for reprints: Dr Julio Garcia Moreno, Instituto de Salud Publica de Chile, Marathon 1000, Casilla 48, Santiago, Chile

Accepted for publication 26 May 1986 contribute to appreciable under-reporting of cases. In addition, though many developing countries maintain statistical data on notifiable diseases such as gonorrhoea and syphilis, detailed information regarding these statistics is often not available to groups such as the World Health Organisation or the Pan American Health Organisation. ${ }^{4}$ The above circumstances typify the situation in many Latin American countries.

In Chile, gonorrhoea is a notifiable disease. In 1982 the incidence of gonorrhoea was reported to be $100 \cdot 8$ cases per 100000 people. $^{5}$ This incidence has not changed appreciably since 1979 (when there were 98.4 cases per 100000 ) when national statistics were collected for the first time. Before 1979 statistics had been maintained for only metropolitan areas. In 1964 the incidence of gonorrhoea in metropolitan areas of Chile per 100000 was 134.9 , whereas in 1982 it was $96 \cdot 4$. It should be noted that the national incidence in Chile is well below that cited by countries such as 
Canada and Sweden; ${ }^{2}$ though these figures may be severely underestimated due to incomplete reporting and undernotification of cases. ${ }^{5}$

In Chile the primary regimen for treating uncomplicated acute gonorrhoea is penicillin (4.8 MIU aqueous procaine penicillin $G$, intramuscularly, with $1.0 \mathrm{~g}$ probenecid orally in a single dose) and the second line treatment is tetracycline (in an initial dose of $1.5 \mathrm{~g}$ followed by $500 \mathrm{mg}$ orally four times daily for four days). ${ }^{6}$ To ascertain whether treatment regimens are effective, it is essential to evaluate treatment success or failure with the in vitro susceptibility of the strains to antimicrobial agents. The present study was therefore undertaken to evaluate clinically the two treatment regimens (penicillin and tetracycline) used in Chile, to assess the sensitivity of the gonococcal isolates to eight antibiotics (thereby developing a Chilean susceptibility data base for future reference) and to screen for the presence of PPNG strains. Previous studies with $N$ gonorrhoeae in Chile had not identified PPNG isolates. ${ }^{\text {? }}$

\section{Patients and methods}

\section{CLINICAL STUDIES}

We screened 1219 patients with a clinical diagnosis of uncomplicated acute gonorrhoea who attended three venereal disease centres in Santiago from August 1982 to July 1983. Of these, 540 (398 men, 142 women) were included in the study. We excluded 679 for one of the following reasons: concomitant syphilis, allergy to the antibiotics in the study, prostitution, pregnancy, antibiotic treatment within two weeks immediately preceding the consultation, non-compliance with the requirement for a test of cure seven days after the initial visit, or a negative culture for $\mathbf{N}$ gonorrhoeae at the first visit.

Patients were randomly treated with one of two regimens: 4.8 MIU aqueous procaine penicillin $G$, intramuscularly, plus $1 \mathrm{~g}$ probenecid orally in one single dose, or tetracycline in an initial dose of $1.5 \mathrm{~g}$ followed by $500 \mathrm{mg}$ orally four times a day for four days. A total of 218 men and 85 women were treated with penicillin, and 180 men and 57 women were treated with tetracycline. All patients who were culture positive seven days after treatment were considered to be treatment failures.

\section{IDENTIFICATION AND STORAGE OF ISOLATES}

Gram stained smears of clinical specimens were completed at the clinics, where isolates were also streaked directly on to Thayer-Martin medium. Identification of $N$ gonorrhoeae was completed using standard criteria (oxidase, colonial morphology, Gram stain, and sugar utilisation). ${ }^{8}$ Colonies were screened for $\beta$ lactamase production using the chromogenic cephalosporin powder, Nitrocefin. ${ }^{9}$
Isolates were stored at $-70^{\circ} \mathrm{C}$ in medium containing $20 \%$ glycerol or were lyophilised in $2 \%$ skimmed milk. ${ }^{10}$ About 250 strains were forwarded to the Antimicrobials and Molecular Biology Division, Laboratory Centre for Disease Control, Ottawa, Canada for reference testing and for further biological and genetic characterisation.

\section{ANTIMICROBIAL SUSCEPTIBILITY TESTING}

The minimum inhibitory concentration (MIC) for the isolates of penicillin, ampicillin (Ayerst Laboratories, Montreal, Canada), tetracycline (Laboratorio Chile, Santiago, Chile), spectinomycin (Upjohn Company of Canada, Don Mills, Ontario), thiamphenicol (Laboratorio Chile, Santiago, Chile), erythromycin (Laboratorio Chile, Santiago, Chile), cefotaxime (Hoechst-Chile, Santiago, Chile), and cefuroxime (Glaxo Group Research, Middlesex, England) was measured by an agar dilution method with chocolate agar. ${ }^{1011}$ Control strains included WHO reference strains III, V, and VII and several PPNG isolates. ${ }^{10}$

\section{ANALYSIS OF AUXOTYPE, PLASMID CONTENT, AND SEROTYPE}

All genetic, serological, and molecular tests were carried out at the Laboratory Centre for Disease Control, Ottawa, Canada. Isolates were characterised by nutritional requirement according to the typing method of Hendry and Stewart. ${ }^{12}$ Plasmid content was analysed using the methods of Dillon et al. ${ }^{13}$ Serological reagents and control strains were kindly supplied by Dr S Bygdeman, Karolinska Institute, Stockholm, Sweden. The serological typing of strains using monoclonal antibodies to protein I was performed as described by Tam et al ${ }^{14}$ and Bygdeman et al..$^{15}$

\section{Results}

\section{RESULTS OF TREATMENT WITH PENICILLIN AND TETRACYCLINE}

Table I shows the efficacy of the penicillin and tetracycline treatment regimens in men and women. Penicillin treatment failed in 16 of 218 men $(7 \cdot 3 \%)$ and five of 85 women $(5.9 \%)$. With tetracycline, treatment failed in four of $180(2 \cdot 2 \%)$ men; no failures were recorded for the 57 women treated with this drug. The

TABLE I Failures of treatment with penicillin and tetracycline for uncomplicated acute gonorrhoea in Chile

\begin{tabular}{llll}
\hline Treatment regimen & Sex & $n$ & $\begin{array}{l}\text { No (\%) } \\
\text { failures }\end{array}$ \\
\hline $\begin{array}{llr}\text { Aqueous procaine penicillin G } \\
\text { with probenecid }\end{array}$ & Men & 218 & $16(7 \cdot 3)$ \\
Tetracycline & Women & 85 & $5(5 \cdot 9)$ \\
& Men & 180 & $4(2 \cdot 2)$ \\
& Women & 57 & 0 \\
\hline
\end{tabular}


difference between treatments was significant $(0.001 \leq p \leq 0.005)$ but not between the sexes $(p \geq$ $0 \cdot 25$ ). Thus treatment with penicillin was effective in $93.1 \%(282)$ of the 303 cases and treatment with tetracycline was effective in $98 \cdot 3 \%$ (233) of 237 cases. Six of the failures with penicillin, in five men and one woman, were attributed to $\beta$ lactamase producing isolates.

\section{SUSCEPTIBILITY TO ANTIMICROBIAL AGENTS}

Table II shows the MICs of eight antimicrobial agents for 674 non-PPNG isolates. More isolates (674) than patients (540) are included in this table as isolates having an MIC of $1 \mathrm{mg} / \mathrm{l}$ or more. Almost all (99\%) isolates were sensitive to erythromycin(MIC $1 \mathrm{mg} / \mathrm{l}$ or less).

Twenty one $\beta$ lactamase producing strains were isolated during the study, and six of these were responsible for penicillin treatment failures (the remaining isolates were recovered from patients who did not comply with the terms of the study). As expected, all 21 PPNG isolates were resistant to penicillin and ampicillin (table III). The $\mathrm{MIC}_{90} \mathrm{~s}$ of the other antibiotics for the PPNG strains were generally within a twofold dilution of the MICs for non-PPNG strains.

TABLE II Minimum inhibitory concentrations of eight antimicrobial agents for non-PPNG isolates from Chile

\begin{tabular}{|c|c|c|c|c|c|c|c|c|c|c|c|c|c|c|}
\hline \multirow{2}{*}{$\begin{array}{l}\text { Antimicrobial } \\
\text { agents }\end{array}$} & \multicolumn{13}{|c|}{ Cumulative \% isolates inhibited by concentration of $(\mathrm{mg} / \mathrm{l})$ : } & \multirow{2}{*}{$\begin{array}{l}\text { No } \\
\text { tested }\end{array}$} \\
\hline & $0 \cdot 008$ & 0.015 & 0.03 & 0.06 & $0 \cdot 12$ & $0 \cdot 25$ & $0 \cdot 5$ & 1 & 2 & 4 & 8 & 16 & 32 & \\
\hline Penicillin & & & & $26^{*}$ & 56 & 84 & 97 & 99 & 100 & & & & & 674 \\
\hline Ampicillin & & & & $28^{*}$ & 64 & 91 & 98 & 100 & & & & & & 674 \\
\hline Cefotaxime & $65^{*}$ & 88 & 94 & 98 & 100 & & & & & & & & & 505 \\
\hline Cefuroxime & & & $22^{*}$ & 53 & 77 & 90 & 97 & 99 & 100 & & & & & 161 \\
\hline Tetracycline & & & & & 5 & 16 & 39 & 91 & 99.9 & 100 & & & & 674 \\
\hline Spectinomycin & & & & & & & & & & & 5 & 87 & 100 & 505 \\
\hline Thiamphenicol & & & & & & & $39 *$ & 71 & 94 & 99 & 100 & & & 674 \\
\hline Erythromycin & & & & 8 & 21 & 50 & 86 & 99 & 100 & & & & & 674 \\
\hline
\end{tabular}

PPNG = Penicillinase producing Neisseria gonorrhoeae.

$*=\leq$.

from patients with a positive initial culture who subsequently failed to comply with the terms of the study were included. More than $50 \%$ of the isolates were inhibited by $0.12 \mathrm{mg} / \mathrm{l}$ of penicillin and ampicillin and over $90 \%$ were inhibited at a concentration of $0.5 \mathrm{mg} /$ 1. The $\mathrm{MIC}_{90} \mathrm{~s}$ of tetracycline, cefotaxime, and cefuroxime were $1 \cdot 0,0 \cdot 3$, and $0 \cdot 25 \mathrm{mg} / \mathrm{l}$, respectively. Though all isolates were sensitive to spectinomycin, $13 \%$ showed rather high MICs $(32 \mathrm{mg} / \mathrm{l})$. MICs to thiamphenicol were also high, with $61 \%$ of the isolates
AUXOTYPE AND PLASMID CONTENT

Table IV shows plasmid content and auxotype of 226 non-PPNG and 21 PPNG isolates. The 21 PPNG isolates were of the wild type (non-requiring) auxotype and carried the Asian type penicillinase producing plasmid (4.5 megadalton) as well as the transfer (24.5 megadalton) and cryptic ( 2.6 megadalton) plasmids. They were typed serologically as group WII/III. Twenty of the PPNG strains were serovar Bajk and

TABLE III Minimun inhibitory concentrations of eight antimicrobial agents for 21 penicillinase producing $N$ gonorrhoeae strains isolated in Chile

\begin{tabular}{|c|c|c|c|c|c|c|c|c|c|c|c|c|c|c|c|}
\hline \multirow{2}{*}{$\begin{array}{l}\text { Antimicrobial } \\
\text { agents }\end{array}$} & \multicolumn{15}{|c|}{ Cumulative $\%$ isolates inhibited by concentration of $(\mathrm{mg} / \mathrm{l})$ : } \\
\hline & 0.008 & $0 \cdot 015$ & 0.03 & 0.06 & $0 \cdot 12$ & $0 \cdot 25$ & $0 \cdot 5$ & 1 & 2 & 4 & 8 & 16 & 32 & 64 & 128 \\
\hline \multirow{7}{*}{$\begin{array}{l}\text { Penicillin } \\
\text { Ampicillin } \\
\text { Cefotaxime } \\
\text { Cefuroxime } \\
\text { Tetracycline } \\
\text { Spectinomycin } \\
\text { Thiamphenicol } \\
\text { Erythromycin }\end{array}$} & & & & & & & & & & & & & & 14 & \\
\hline & & & & & & & & & & & & & & 5 & 100 \\
\hline & 48 & 96 & 100 & 10 & 96 & 100 & & & & & & & & & \\
\hline & & & & & & & 38 & 100 & & & & & & & \\
\hline & & & & & & & & & & & 5 & 95 & 100 & & \\
\hline & & & & & & & & 57 & 100 & & & & & & \\
\hline & & & & & 5 & 72 & 100 & & & & & & & & \\
\hline
\end{tabular}


TABLE IV Relation between auxotype and plasmid content of 226 non-PPNG and 21 PPNG strains isolated in Chile

\begin{tabular}{|c|c|c|c|c|c|c|}
\hline \multirow[b]{3}{*}{ Auxotype } & \multicolumn{6}{|c|}{ Plasmid content (megadaltons) } \\
\hline & \multicolumn{5}{|c|}{ Non-PPNG strains } & \multirow{2}{*}{$\frac{P P N G \text { strains }}{2 \cdot 6+4 \cdot 5+24 \cdot 5}$} \\
\hline & $2 \cdot 6$ & $2 \cdot 6+24 \cdot 5$ & $24 \cdot 5$ & No plasmid & Total & \\
\hline $\begin{array}{l}\text { NR } \\
\text { Pro- } \\
\text { Orn }^{-} \\
\text {Pro-Orn }^{-} \\
\text {Pro }^{-} \text {Meth }^{-}\end{array}$ & $\begin{array}{r}79 \\
64 \\
4 \\
3 \\
2\end{array}$ & $\begin{array}{r}30 \\
28 \\
6 \\
5 \\
1\end{array}$ & 3 & 1 & $\begin{array}{r}110 \\
95 \\
10 \\
8 \\
3\end{array}$ & 21 \\
\hline Total & 152 & 70 & 3 & 1 & 226 & 21 \\
\hline
\end{tabular}

PPNG = penicillinase producing Neisseria gonorrhoeae.

$\mathrm{NR}=$ non-requiring, prototrophic, or wild-type; Pro = proline requiring; Orn = ornithine requiring; Meth $=$ methionine requiring.

one was serovar Bacjk. They probably comprise a single clone.

Plasmid profiles (figure) of non-PPNG strains indicated that four of 226 non-PPNG isolates did not carry a cryptic plasmid; three of these harboured only transfer plasmids.About 67\% (152) of the non-PPNG isolates harboured a cryptic plasmid only, while a further $31 \%$ (70) carried both transfer and cryptic plasmids. The figure shows typical plasmid profiles on agarose gel electrophoresis. One isolate carried the $2 \cdot 6$ megadalton plasmid as a concatenate (lane 5). ${ }^{16}$ This result was verified by DNA-DNA hybridisation studies with the 2.6 megadalton plasmid (data not included).

Most non-PPNG isolates were grouped in two auxotypes; $110 / 226(48 \cdot 7 \%)$ were typed as prototrophic or wild type, and $42 \%(95 / 226)$ were typed as proline requiring (table IV). The remaining $9.3 \%(21)$ isolates required ornithine, proline and ornithine, or proline and methionine. The 24.5 megadalton transfer plasmid was unusually present in strains from all auxotypes.

\section{Discussion}

During the 1980s PPNG strains were identified or reported from several countries in South America. ${ }^{16} 17$ A key finding in the present study has been the identification, for the first time in Chile, of these strains. The incidence of these strains corresponded to $3 \cdot 1 \%(21 /$ 674 ) of the total number of strains initially isolated, and their presence contributed to penicillin treatment failure during the course of the study. The identification of PPNG strains underlined the necessity of establishing laboratory screening programmes for PPNG strains in Chile to detect and monitor their spread. All PPNG isolates studied were identical serologically, genetically, and biologically, which indicated that one PPNG strain was circulating in the population being screened during the study. Thus the future importation of new PPNG strains into the
Santiago area will be detectable by serological and genetic means.

The Chilean Ministry of Health recommended treatment with $4.8 \mathrm{MIU}$ aqueous procaine penicillin $\mathrm{G}$ by intramuscular injection plus $1 \mathrm{~g}$ oral probenecid as the first choice treatment for uncomplicated acute gonorrhoea. A tetracycline regimen $(1.5 \mathrm{~g}$ followed by $500 \mathrm{mg}$ four times daily for four days) was recommended as second choice. In the present study, the penicillin regimen was effective for $93 \cdot 1 \%$ of the cases treated, whereas tetracycline treatment was effective in $98.3 \%$ of the cases treated. Should the number of cases due to PPNG strains in Chile increase, penicillin treatment would be even less effective. A recent report by the World Health Organisation on treatments in the control of sexually transmitted diseases states that regimens "achieving less than $95 \%$ cure rates have been historically associated with rapid increases in the prevalence of resistant organisms", and also that regimens with cure rates of $90-95 \%$ should be used with caution, as resistant isolates may be selected. ${ }^{19}$ The treatment data from this study underline the correctness of these statements. With a cure rate of 93.1\% after penicillin treatment, the presence of resistant isolates is predicted. These predictions were confirmed by in vitro studies that showed the presence of PPNG isolates for the first time in Chile and showed that about $3 \%$ of the non-PPNG isolates were resistant to $0.5 \mathrm{mg} / \mathrm{l}$ penicillin. The treatment failure rates observed with penicillin resulted in a re-evaluation of treatment recommended by the Chilean Ministry of Health (tetracycline is now the first choice treatment for certain cases of acute uncomplicated gonorrhea).

Critical MICs of several antibiotics have been established at which appreciable treatment failures may be expected if recommended doses are used (these are generally related to the maximum concentration attainable in serum or other body tissues). Historically, an MIC of 0.5 units $/ \mathrm{ml}$ penicillin or 1.0 $\mathrm{mg} /$ tetracycline has been associated with appreciable treatment failure..$^{20}$ In the present study increasing 


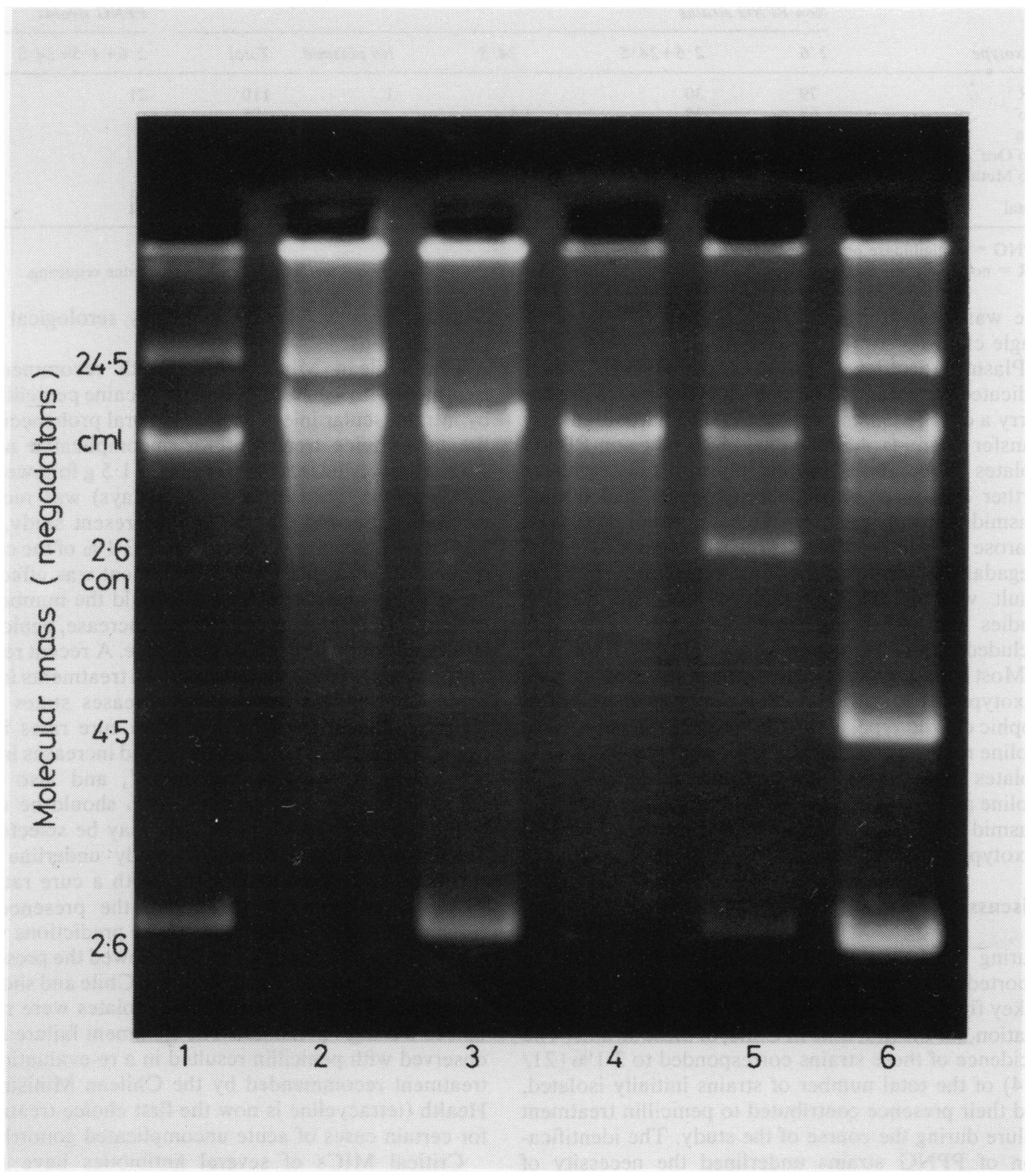

FIGURE Lane $1=$ strain $702,(2 \cdot 6$ and $24 \cdot 5$ megadalton plasmids); lane $2=$ strain $1102(24 \cdot 5$ megadalton plasmid); lane $3=$ strain $652(2 \cdot 6$ megadalton plasmid $) ;$ lane $4=$ strain 811 (plasmid free $) ;$ lane $5=$ strain $1328(2 \cdot 6$ megadalton plasmid and concatenate); lane $6=P P N G \operatorname{strain} 1427(2 \cdot 6,4 \cdot 5$, and $24 \cdot 5$ megadalton plasmids $)$. $\mathrm{Cml}=$ chromosomal . 
treatment failures were observed at both of these MIC levels (data not shown). The overall sensitivity of gonococcal strains to tetracycline is particularly important in Chile as it is a recommended treatment and because its low cost makes it easily available to any health service. Though tetracycline treatment was effective in this study, continued monitoring of susceptibility is essential as a small decrease in levels of susceptibility will be accompanied by large increases in the number of tetracycline treatment failures. The reduced in vitro sensitivity of the isolates to thiamphenicol may reflect the non-prescription use of chloramphenicol, a cross reacting antibiotic, in the population tested.

In comparing MIC data presented in this study with MIC data on penicillin collected by Fernandez et al in 1979 , it is interesting to note that the isolates in this study were less sensitive to penicillin $\left(\mathrm{MIC}_{50} 0.25 \mathrm{mg} / \mathrm{l}\right.$ ) than the 53 isolates characterised in the previous study

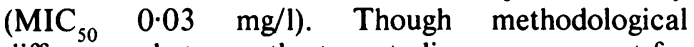
differences between the two studies may account for some of the differences, the apparent decrease in susceptibility of gonococcal isolates to penicillin in the present study suggests that further in vitro surveillance is warranted.

Over $91 \%$ (226) of the 247 isolates typed auxanographically comprised two auxotypes - wild type and proline requiring. The remaining isolates comprised only three auxotypes. The limited number of auxotypes reflects reports from other developing countries in that few auxotypes were present and that proline requiring and wild type auxotypes predominated. ${ }^{23-26}$ Additional auxotypes in these countries tend to require arginine (ornithine in the present study), proline and arginine, or proline and methionine, as was observed in this study. By contrast, several nations from the northern hemisphere have reported the isolation of up to 20 distinct auxotypes. ${ }^{27} 28$ In some of these areas proline requiring strains no longer predominate and have been replaced by strains such as those requiring arginine and other compounds, or requiring proline, citrulline, and uracil. ${ }^{27.29}$ The auxotype distribution is reflected in the antimicrobial susceptibility of the isolates. For example, wild type and proline requiring strains tend to be moderately susceptible to penicillin $(\mathrm{MIC}=0.063$ $0.25 \mathrm{mg} / \mathrm{l}$ ) as opposed to strains more sensitive to penicillin, which require arginine and other supplements. ${ }^{27} 2930$ In the data presented in this study, most strains were moderately susceptible and, as might be predicted, were predominantly wild type or proline requiring.

Geographical variation in plasmid carriage has been noted. In North America $8-21 \%$ of non-PPNG isolates screened carried transfer plasmids, ${ }^{29_{31}}$ whereas over $30 \%$ of strains from the Far East carried transfer plasmids. ${ }^{2631}$ In Chile $32 \%(73 / 226)$ of the isolates carried transfer plasmids. It was especially notable that this plasmid was observed in all auxotypes. As the transfer of the penicillinase plasmid between gonococci is mediated by the transfer plasmid, its high prevalence and presence in all auxotypes may foreshadow an epidemic spread of the penicillinase plasmid to other strains. The penicillinase producing isolates seemed to be a single clone. Though the plasmid was of the Asian type, the serovar of the strains has been observed worldwide (Bygdeman, personal communication) and the source of this outbreak is therefore impossible to pinpoint. Future genetic and serological studies on PPNG and non-PPNG strains from Chile should provide interesting data on the spread of PPNG strains.

In conclusion, this study emphasises the importance of establishing a clinical and laboratory surveillance programme to develop specific national guidelines on treatment as well as national data bases on susceptibility of strains to antimicrobials. After completion of the present study, new treatment guidelines and surveillance programmes for PPNG strains were initiated by the Chilean Ministry of Health. In addition, the identification of PPNG strains during the study has led to plans for an expanded PPNG strain surveillance programme as well as for specific health promotion programmes.

This work was supported by a grant from the International Development Research Centre, Ottawa, Canada. We thank Dr Fernando Zacarias, Division of Venereal Disease Control, Center for Prevention Services, Centers for Disease Control, Atlanta, for his encouragement and advice during the conduct of this study.

\section{References}

1. Barnes RC, Holmes KK. Epidemiology of gonorrhoea: current perspectives. Epidemiol Rev 1984;6:1-30.

2. Bureau of Epidemiology. Sexually transmitted diseases in Canada - 1984. Ottawa, Canada: Health and Welfare Canada, 1985:6-17.

3. Lind I. Bollerup AC, Gadeberg OV, Reimann K, Bentzon HW. Activities of the WHO collaborating centre for reference and research in gonococci, Copenhagen, for the year 1983. WHO/ VDT/RES/GON 84 1984;144:1-15.

4. Communicable Disease Control, Pan American Health Organisation. Sexually transmitted diseases. Epidemiological Bulletin 1981:2:1-4.

5. Villalobos D. E studio de las ETS en Chile 1982-1983. Santiago, Chile: Ministerio de Salud Publica de Chile, 1983.

6. Moreno JG, Lolic H, Morabo A, Salvo A, Urra I, Villalobos D. Normas para el control de las enfermedades de transmission sexual. Santiago, Chile: Feliciana 1980:1-55. 
7. Garcia J, Prat $\mathbf{M}$, Arroyave R. Estadio de sebsibilidad in vitro de Neisseria gonorrhoeae a penicilina y tetraciclina. Boletin del Instituto de Salud Publica de Chile 1980;21:74-6.

8. Morello JA, Bohnhoff M. Neisseria and Branhamella. In: Lennette EH, Balows A, Hausler WJ, Truant JP, eds. Manua of clinical microbiology. 3rd ed. Washington DC: American Society of Microbiology, 1980:111-30.

9. O'Callaghan $\mathrm{CH}$, Morris A, Kirby SM, Shingler AH. Novel method for detection of $\beta$-lactamase by using chromogenic cephalosporin substrate. Antimicrob Agents Chemother 1972;1:283-8.

10. Dillon JR. Laboratory methods for Neisseria gonorrhoeae (MIC, auxotype screening for PPNG). Ottawa, Canada: Laboratory Centre for Disease Control, National Health, and Welfare, 1983 (Catalogue No H47-58/1983E).

11. Thornsberry C, Gavan TL, Gerlach EH. New developments in antimicrobial agent suscepitibility testing. Washington, DC: American Society of Microbiology, 1977. Cumitech 6 .

12. Hendry AT, Stewart 10. Auxanographic grouping and typing of Neisseria gonorrhoeae. Can J Microbiol 1979;25:512-21.

13. Dillon JR, Pauzé M, Yeung K-H. Spread of penicillinaseproducing and transfer plasmids from the gonococcus to Neisseria meningitidis. Lancet 1983;i:779-81.

14. Tam MR, Buchanan TM, Sandström EG, et al. Serological classification of Neisseria gonorrhoeae with monoclonal antibodies. Infect Immun 1982;36:1042-53.

15. Bygdeman S, Danielsson D, Sandström E. Gonococcal W serogroup in Scandinavia. A study with polyclonal and monoclonal antibodies. Acta Pathol Microbiol Immunol Scand [B] 1983;91:239-305.

16. Johnson SR, Anderson BE, Biddle JW, Perkins GH, DeWitt WE. Characterization of concatemeric plasmids of Neisseria gonorrhoeae. Infest Immun 1983;40:843-6.

17. Riou JY, Courvalin P. Neisseria gonorrhoeae plasmids: theoretical study and practical consequences. WHO/VDT/ $R E S / G O N 85$ 1985; 146:24.

18. Dillon JR. Pauzé M, Yeung K-H. Molecular and epidemiological analysis of penicillinase producing strains of Neisseria gonorrhoeae isolated in Canada 1976-84: evaluation of new auxotypes and $\beta$ lactamase encoding plasmid. Genitourin Med 1986;62:151-7.
19. World Health Organisation. Current treatments in the control of sexually transmitted diseases. WHO/VDT/83;43:1-45.

20. Sparling PF. Antibiotic resistance in Neisseria gonorrhoeae. Med Clin North Am 1972;56:1133-44.

21. Karney WW, Pederson AFB, Nelson M, Adams H, Pfeifer RT, Holmes KK. Spectinomycin versus tetracycline for the treatment of gonorrhoea. N Engl J Med 1977;296:889-94.

22. Fernandez H, Otth L, Cartes M, Bittner M. Sensibilidad in vitro de Neisseria gonorrhoeae a 5 penicilinas. Rev Med Chil 1979;107:416-8.

23. Odugbemi TO, Brown ST, Biddle J, et al. Plasmid profile, serogrouping, and auxotyping of Neisseria gonorrhoeae isolates from Africa. British Journal of Venereal Diseases 1983;59:413.

24. Yvert F, Frost E, Guibourdenche M, Riou JY, Ivanoff B. Auxotypes and serogroups of penicillinase producing and nonproducing strains of Neisseria gonorrhoeae isolated in Franceville, Gabon. Genitourin Med 1985;61:99-102.

25. Perine PL, Totten PA, Knapp JS, Holmes KK, Bentsi C, Klufio CA. Diversity of gonococcal plasmids, auxotypes, and serogroups in Ghana. Lancet 1983;i:1051-2.

26. Odugbemi TO, Whittington WL, DeWitt W, et al. Epidemiologial characterisation of Neisseria gonorrhoeae isolates from the Far East. British Journal of Venereal Diseases 1983;59:285-8.

27. Ansink-Schipper MC. Auxanographic typing of Neisseria gonorrhoeae isolated in the Netherlands. Amsterdam, the Netherlands: University of Amsterdam, 1985. Ph D thesis.

28. Carifo K, Catlin BW. Neisseria gonorrhoeae auxotyping: differentiation of clinical isolates based on growth responses on chemically defined media. Applied Microbiology 1973;26:223-

29. Dillon JR, Pauzé M. Resistance to antimicrobial agents. What next for Neisseria gonorrhoeae? Sex Transm Dis 1984;11 suppl:353-9.

30. Stewart IO, Hendry AT. Association between the auxogroup of Neisseria gonorrhoeae and the minimal inhibitory concentration of penicillin. Sex Transm Dis 1979;6:247-52.

31. Roberts M, Piot P, Falkow S. The ecology of gonococcal plasmids. J Gen Microbiol 1979;114:491-4. 